\title{
NONSURGICAL TREATMENT OF PATHOLOGICAL CYSTS OF DENTAL ORIGIN
}

\author{
Dr. Syed Manzoor ul haq Bukhari, *Dr. Amrita Dhakal Sharma \\ Dept of conservative and endodontics, KVG dental college, Kurungibagh, Sullia, Dakshin kannad, \\ Karnataka state, India \\ * KVG Medical college, Kurungibagh, Sullia, Dakshin kannad, Karnataka state, India
}

\section{To access $\&$ cite this article}

Website: jidam.idamadras.com

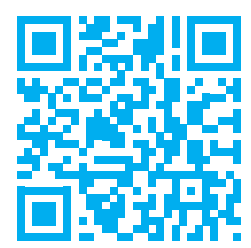

DOI:10.37841/jidam_2020_V7_I4_02

\section{Address for Correspondence:}

Dr.Syed Manzoor ul haq Bukhari, MDS., Dept of conservative and endodontics, KVG dental college,

Kurungibagh, Sullia, Dakshin kannad Karnataka state, India

Email id: manzoorulhaq05@gmail.com

\section{ABSTRACT}

BACKGROUND: Radicular cysts (RC) of dental origin are slow-growing lesions which are asymptomatic in most of the cases. The management of RCs is still existing over a debate. Therefore, we present a study of nonsurgical management of pathological cysts of dental origin.

AIM: To study the success of non-surgical management of patients presenting with pathological cysts of dental origin in terms of healing and recurrence.

MATERIALS AND METHODS: Prospective study was done in 25 patients presenting with pain and swelling in the Department of conservative and endodontics for a period of 2 years. The cystic cavity was opened and drained using various methods such as decompression, aspiration-irrigation, placement of intracanal $\mathrm{Ca}$ $(\mathrm{OH}) 2$ and lesion sterilization.

RESULTS: The success rate of nonsurgical treatment was $80 \%$ while $12 \%$ of cases presented with recurrence and $8 \%$ of cases had delayed healing.

CONCLUSION: Follow-up and assessment of healing are essential after nonsurgical treatment of the cysts. The surgical approach is used for cases which are refractory to nonsurgical method.

KEYWORDS: Nonsurgical method, $\mathrm{Ca}(\mathrm{OH}) 2$ decompression, aspiration-irrigation, Cyst. 


\section{Introduction :}

Dental cysts are cavities containing fluid or soft tissue material lined by epithelium ${ }^{1}$. It can be traced at the crown of an un-erupted tooth or at the root tip of a necrotic tooth. Dental cysts are formed due to repeated trauma, infections and poor dental hygiene $^{2}$. It is also linked to genetic syndromes such as Gorlin's syndrome ${ }^{3}$. Follicular dental cyst, keratocyst, retromolar dental cyst, eruption dental cyst, radicular dental cyst and residual dental cyst are the six types of dental cysts ${ }^{2}$.A cyst is usually diagnosed incidentally on radiographic examination, however few patients present with pain or swelling ${ }^{4}$. Endodontic therapy restores the involved teeth using the nonsurgical treatment such as enucleation, decompression, calcium hydroxide placement or aspiration irrigation technique and repair theratpy ${ }^{5}$. Hence the aim of the present study was to evaluate the effect of nonsurgical management of patients presenting with radicular cysts.

\section{MATERIALS AND METHODS :}

We have studied 25 patients prospectively, who presented with swelling and pain to the department of conservative and endodontic for a period of 24 months in KVG medical college and hospital.

Inclusion criteria:

Positive findings on intraoral examination.

Radiology revealing radiolucency correlating with clinical finding.

\section{EXCLUSION CRITERIA:}

Patients having systemic diseases like hypertension, diabetes mellitus or Immunocompromised. Patients not willing for non-surgical treatment.

\section{METHODS:}

Clinical details along with all the necessary findings were noted. Dental history of trauma, infection with duration and progression of pain and swelling were taken. Both extra-oral and intra-oral examination was done, the location and the size of the swelling were noted. Provisional diagnosis of cyst was made. The patient was then referred for orthopantogram, intra-oral periapical and occlusal radiograph for the exact location, size and confirmation of the clinical diagnosis. Cold and electric test was done to check the pulp vitality. If the root canal was found to be infected, access cavity preparation was done in the involved tooth and the pus was expressed out. Patients were counselled regarding the merits and demerits along with the complications of each procedure. 25 patients were willing to opt for nonsurgical management, the fluid was then sent to the department of pathology for cystic diagnosis and to rule out any malignant pathology-Cleaning and shaping of the root canals were done using hand instrumentation $\mathrm{K}$ file. The opening was sealed with an intermediate restoration. On the second visit, the intermediate restoration was removed and various non- surgical methods such as aspiration and irrigation technique of draining the cystic fluid using a bucco-palatal approach with 18 gauge needle, intra-canal placement of calcium hydroxide beyond the apex, lesion sterilization by using a paste of ciprofloxacin, metronidazole and minocycline antibiotics, decompression technique by using negative pressure created by a suction aspirator connected to micro 22-gauge needle inserted in the root canal were used on different patients depending upon the location and patients compliance. After two weeks, permanent restoration as placed and the case was followed up with clinical and radiographic investigation every 6 months for a period of 24 months. If pain or swelling reappeared or if there was an increase the size of the radiolucency or if there was radiographical evidence of root resorption then surgical treatment was given to the patients and the conservative or nonsurgical treatment was considered a failure. The success of the case was determined by comparing the apical radiolucency on the pre- and post-operative periapical radiograph. The periapical index (PAI) was used for scoring, single observer was used to eliminate intra-observer variability. All records were digitalized and radiographs were observed under magnification. PAI scores of 1-2 were considered success and 3-5 were considered a failure.

\section{RESULTS:}

Table no. 1. shows the distribution of cases according to age.

\begin{tabular}{|c|c|}
\hline Age & No. of cases \\
\hline $25-30$ & 03 \\
\hline $31-35$ & 08 \\
\hline
\end{tabular}




\begin{tabular}{|l|l|}
\hline $36-40$ & 05 \\
\hline $41-45$ & 08 \\
\hline
\end{tabular}

\begin{tabular}{|c|c|}
\hline$>45$ & 01 \\
\hline Total & $\mathbf{2 5}$ \\
\hline
\end{tabular}

In the present study maximum number of patients were seen in the $3^{\text {rd }}-4^{\text {th }}$ decade. 3 cases were seen in $25-30$ years and 1 case was noted in $>45$ years of age.

Table no. 2. shows the distribution of cases according to symptoms.

\begin{tabular}{|c|c|}
\hline Symptoms & No. of cases \\
\hline History of pain & 12 \\
\hline History of discomfort & 01 \\
\hline History of swelling & 12 \\
\hline Total & $\mathbf{2 5}$ \\
\hline
\end{tabular}

As shown in the above table, 12 patients presented with a history of pain and swelling respectively, while 1 patient complained of discomfort.

Table no. 3. shows the distribution of cases according to the site of the lesion.

\begin{tabular}{|c|c|}
\hline Site & No. of cases \\
\hline Mandibular anterior & 08 \\
\hline Mandibular posterior & 02 \\
\hline Maxillary anterior & 10 \\
\hline Maxillary posterior & 05 \\
\hline Total & $\mathbf{2 5}$ \\
\hline
\end{tabular}

According to table 3, the most common location or site of the cyst was anterior maxillary followed by anterior mandible. Posterior maxilla had 5 cases. The least common location was mandibular posteriors with 2 cases.

Table no. 4. shows distribution of cases according to radiographic diagnosis.

\begin{tabular}{|c|c|}
\hline Radiographic diagnosis & No. of cases \\
\hline Cystic & 18 \\
\hline Solid-cystic & 07 \\
\hline Total & $\mathbf{2 5}$ \\
\hline
\end{tabular}

According to the above table, the most common radiographic finding was cystic with 18 cases. Solid-cystic was observed in 7 cases in the present study.

Table no. 5. shows the distribution of cases according to cytological diagnosis.

\begin{tabular}{|c|c|}
\hline Cytological findings & No. of cases \\
\hline Benign cystic lesion & 25 \\
\hline Total & $\mathbf{2 5}$ \\
\hline
\end{tabular}


Benign cystic lesion was confirmed as the cystic diagnosis of all cases in the present study

Table no. 6. shows the distribution of cases according to treatment modalities.

\begin{tabular}{|c|c|}
\hline Treatment modalities & No. of cases \\
\hline Aspiration-irrigation & 06 \\
\hline CAOH & 14 \\
\hline Decompression & 03 \\
\hline Lesion sterilization & 02 \\
\hline Total & $\mathbf{2 5}$ \\
\hline
\end{tabular}

According to the above table, the most common treatment modality done on patient was $\mathrm{Ca}(\mathrm{OH})_{2}$ placement, followed by aspiration-irrigation and decompression. The least common treatment modality done was lesion sterilization.

Table no. 7. shows no of cases with successful management of the pathological cyst of dental origin.

\begin{tabular}{|c|c|c|}
\hline Follow-up of the cases & No. of cases & Percentage \\
\hline Successful management & 20 & 80 \\
\hline Recurrence & 03 & 12 \\
\hline Delayed healing & 02 & 8 \\
\hline Total & $\mathbf{2 5}$ & $\mathbf{1 0 0}$ \\
\hline
\end{tabular}

As shown in table no. 7, the success rate of nonsurgical treatment was $80 \%$ while $12 \%$ of cases presented with recurrence and $8 \%$ of cases had delayed healing.

\section{DISCUSSION:}

Pathological dental cyst treatment is conundrum ${ }^{6}$. Nonsurgical treatment is not a recent discovery, it started in 1952 when Summer, Ostrander and Crowley introduced I shaped rubber dam wick in the periapical region which was to be changed every 2 weeks. The main aim of this procedure was to initiate the healing process by relieving the cavity pressure of the cyst ${ }^{7}$. Bhaskar et al 1972 description of the nonsurgical method for the treatment of the dental cysts (RC) has undergone changes and it has shown massive success in the treatment of radicular cysts ${ }^{8}$. Reit and Goran-Grondahl in their study reported that nonsurgical endodontic treatment modality was more preferred than periapical surgery ${ }^{9}$. In the present study, most of the cases were in the $3^{\text {rd }}-4^{\text {th }}$ decade with 8 cases. 3 cases were seen in 25-30 years and 1 case was noted in $>45$ years of age which is in contrast to a study done by Shah Naseem ${ }^{10}$, where he observed a maximum number of cases in 10-20 years of age. In the present study, most of the patients presented with pain and swelling while in a study by Shah Naseem ${ }^{10}$ most patients presented with painless gumboil. The most common location or site of the cyst was maxillary anteriors followed by mandibular anteriors in the present study, the findings are in line with the study done by Shah Naseem ${ }^{10}$, where he reported maxillary anteriors as the most common teeth affected followed by mandibular anteriors.

In the present study, definitive diagnosis was based on radiographic examination where most cases showed radiolucency due to cystic nature of the fluid and cytological evidence of benign cystic lesion. Shah Naseem ${ }^{10}$ in their study reported radiolucency of various sizes in the periapical region. The treatment choice is determined by various factors such as origin, characteristics and the extent of the lesion, relationship with the structures of origin and the surroundings and the compliance of the patients. In the present study, the most common treatment modality done on patients was the placement of $\mathrm{Ca}(\mathrm{OH})_{2}$ followed by aspiration-irrigation. The least common treatment modality done was lesion sterilization. Previous Case reports ${ }^{11}$ have 
used similar treatment modalities in their study. $\mathrm{Ca}(\mathrm{OH})_{2}$ has antibacterial action as it acts on the cytoplasmic membranes of the bacteria and it also damages bacterial $\mathrm{DNA}^{12}$. Decompression is a procedure which can remove the cystic content which has microbial load by creating negative pressure and enhances the process of healing. Due to the decrease in inflammatory mediators, the cells are deprived of growth factors which leads to programmed cell death known as apoptosis which leads to regression of the cyst/lesion ${ }^{13}$. In aspiration and irrigation technique 18-gauge needle was used and the cystic fluid was aspirated using the bucco-palatal approach. Lesion sterilization was done by using a paste of ciprofloxacin, metronidazole and minocycline. In the present study, the criteria for success after 2 years of follow-up every 6 months was as follows:

1. Absence of pain, swelling and discomfort.

2. Proper healing and repair process.

3. Radiographic evidence of the healing process.

The success rate of nonsurgical treatment was $80 \%$ while $12 \%$ cases presented with recurrence and $8 \%$ of cases had delayed healing. Studies have shown that nonsurgical management of periapical lesion/cyst has a success rate of upto $85 \%$ which is similar to our study. Murphy $\mathrm{WK}^{14}$ in their study after nonsurgical management has reported $94.4 \%$ complete and partial healing of the periapical lesion. Shah Naseem ${ }^{10}$ reported $84.4 \%$ successful conservative treatment and $15.6 \%$ patients had to undergo surgery. He also reported $50 \%$ failure at or after 1-year treatment. Wound healing is a complex process; thus, healing of the lesion was assessed in this study by using the periapical index ${ }^{15}$. Wound healing after nonsurgical treatment of the dental cysts follows the principles of connective tissue wound healing of the body.

\section{CONCLUSION:}

The blood supply and the nerve supply may get damaged with a larger cyst, if treated surgically. Therefore, nonsurgical management, is unavoidable in such cases. Most of the cysts resolve and heal following the conservative method. However, follow-up and assessment of healing are essential. The surgical approach is used for cases which are refractory to the nonsurgical method.

\section{REFERENCES :}

1. Kramer IR, Pindborg JJ, Shear M. Histologic typing of odontogenic tumors; WHO; 1992. pp.35-6.

2. Ramachandra P, Maligi P, Raghuveer HP. A cumulative analysis of odontogenic cysts from major dental institutions of Bangalore city: A study of 252 cases. JOMFP. 2011 Jan;15(1):1.

3. Manjima S, Naik Z, Keluskar V, Bagewadi A. Multiple jaw cysts-unveiling the GorlinGoltz syndrome. Contemporary Clinical Dentistry.2015 Mar;6(1): 102.

4. Penumatsa NV, Nallanchakrava S, Muppa R, Dandempally A, Panthula P. Conservative approach in the management of radicular cyst in a child: Case report. Case report in Dentristy.2013 Feb.

5. Karunkarannd JV, Abraham CS, Karthik AK, Jayaprakash N. Succesful nonsurgical management of periapical lesions of endodontic origin: a conservative orthograde approach. Journal of pharmacy \&bioallied sciences. 2017 Nov; (1): 246.

6. Morse DR, Bhambhani SM. A dentists' dilemma: Nonsurgical endodontic therapy or periapical surgery for teeth with apparent pulpal pathosis and an associated periapical radiolucent lesion. Oral surg oral med oral pathol 1990; 70:333-40.

7. Summer RF, Ostrander FD, Crowley M.C.Clinical endodontics: a manual of scientific endodontics. Philadelphia: WB Saunders, 1956.

8. Bhaskar SN. Nonsurgical resolution of radicular cysts. Oral surg oral med oral pathol 1972; 34:458-468.

9. Reit C, Goran-Grondahl H.Management of periapical lesions in endodontically treated teeth. Swed Dent J 1984; 8:1-7.

10. Shah N. Nonsurgical management of periapical lesions: a prospective study. Oral Surgery, Oral Medicine, Oral Pathology. 1988 Sep; 66(3): 365-371.

11. Chaudhary S, Tripathi P, Upadhaya Y, Seth 
P. Successful nonsurgical management of a large radicular cyst: A case report with review of literature. Int J Contemp Dent Med Rev. 2015.

12. Diwedi S, Dwivedi CD, Chaturvedi TP, Baranwal HC. Management of a large radicular cyst: A non-surgical endodontic approach. Saudi Endodontic Journal. 2014 Sep; 4 (3): 145.

13. Lin LM, Huang GT, Rosenberg PA. Proliferation of epithelia; cell rests, formation of apical cysts, and regression of apical cysts after periapical wound healing. J endod 2007; 33:908-916.

14. Murphy WK, Kaugars GE, CollettWK, Dodds RN. Healing of periapical radiolucencies after nonsurgical endodontic therapy. Oral surgery, oral medicine, oral pathology.1991 May ; 71(5):620-624.

15. Karunakaran JV, Abraham CS, Karthik AK, Jayaprakash N. Successful nonsurgical management of periapical lesions of endodontic origin: a conservative orthograde approach. Journal of pharmacy \& bioallied sciences. 2017 Nov; 9 (1): 246. 